\title{
Synthesis and Characterization of Carbazole-Benzothiadiazole-Based Conjugated Polymers for Organic Photovoltaic Cells with Triazole in the Main Chain
}

\author{
Eunhee Lim \\ Department of Chemistry, Kyonggi University, San 94-6, Iui-dong, Yeongtong-gu, Suwon-si, Gyeonggi 443-760, Republic of Korea \\ Correspondence should be addressed to Eunhee Lim; ehlim@kyonggi.ac.kr
}

Received 24 February 2013; Accepted 11 June 2013

Academic Editor: Przemyslaw Rupnowski

Copyright (c) 2013 Eunhee Lim. This is an open access article distributed under the Creative Commons Attribution License, which permits unrestricted use, distribution, and reproduction in any medium, provided the original work is properly cited.

We have synthesized a series of carbazole-benzothiadiazole-triazole based copolymers, poly[ $\left(N-9^{\prime}\right.$-heptadecanyl-2,7-carbazole $)$-co(5,5-(4', $7^{\prime}$-di-2-thienyl-2', $1^{\prime}, 3^{\prime}$-benzothiadiazole))-co-((4-(4-butylphenyl)-3,5-diphenyl-4H-1,2,4]triazole))] (PCz3TBTz) by Suzuki coupling polymerization. The optical and electrochemical properties of the copolymers could be tuned by changing the comonomer unit of triazole from $0 \%$ to $80 \%$. Organic photovoltaic (OPV) cells were fabricated by blending the synthesized polymers as a donor and PCBM as an acceptor. The material solubility and film morphology were improved by introducing the triazole unit in the main chain. Improved OPV device performance of $1.74 \%$ was achieved in the presence of an optimal amount of triazole moieties.

\section{Introduction}

Organic photovoltaic (OPV) cells are promising sources of electrical power that have attracted considerable attention because of their efficiency, low cost, and potential renewable energy applications. The prototypical material system consisting of poly(3-hexylthiophene) (P3HT) and [6,6]-phenyl$\mathrm{C}_{61}$ butyric acid methylester (PCBM) normally gives power conversion efficiencies (PCEs) in a range of about 4-5\% [2]. New conjugated polymers with low band gaps that can efficiently harvest solar energy over a broader spectrum are being actively developed. To enhance OPV performance, low-band-gap conjugated materials with appropriate energy levels are required for efficient charge transfer [3]. One successful approach to enhance OPV performance is to arrange electron-donating and electron-accepting units alternately along the conjugated backbone for the use of donor materials in OPVs $[1,4-6]$. Many electron-accepting units such as benzothiadiazole (BT) and diketopyrrolopyrrole (DPP) have been synthesized and utilized in OPVs $[7,8]$.

In organic light-emitting diode (OLED) applications, highly electron-deficient groups such as oxadiazole and triazole $(\mathrm{Tz})$ units have been introduced into the polymer backbone or as the side group as electron transporting units to adjust the charge-injecting and transporting properties of the copolymers [9-11]. More recently, several reports have described improvements in PCE by incorporating electron deficient moieties into the polymer backbone or as side chains [12-16]. The incorporation of electron deficient groups such as thiadiazole or oxadiazole can improve the performance of OPVs by enhancing electron transfer in comparison to the parent polymer. Previously, we reported on polyfluorenes containing various electron transporting units such as benzothiadiazole (BT), oxadiazole, and triazole $(\mathrm{Tz})$ in the main chain $[17,18]$. Interestingly, the photovoltaic properties of the polymers were varied by the introduced electron transporting units and the polymer containing triazole $(\mathrm{Tz})$ showed the improved performance. In this work, we introduce electron-transporting triazole $(\mathrm{Tz})$ units into the well-known carbazole-benzothiadiazole-based copolymer (PCz3TB) by Suzuki polymerization to be used as donors for OPVs. The copolymers were designed to have different feed ratios of comonomer units (benzothiadiazole and triazole). The optical properties, film morphology, and 
photovoltaic characteristics of the polymers are investigated to establish the relationship between molecular structure and device performance.

\section{Experimental}

2.1. Materials. 2,7-Bis $\left(4^{\prime}, 4^{\prime}, 5^{\prime}, 5^{\prime}\right.$-tetramethyl-1 $1^{\prime}, 3^{\prime}, 2^{\prime}$-dioxaborolan-2' -yl)-N-9' -heptadecanyl-carbazole, 4,7-bis(5-bromothiophen-2-yl)benzo[c][1,2,5] thiadiazole, and 3,5-bis-(4bromophenyl)-4-(4-butylphenyl)-4H-[1,2,4]triazole were prepared according to a procedure mentioned in the literature [19]. Aliquat 336, tetrakis(triphenylphosphine)palladium(0) $\left(\mathrm{Pd}\left(\mathrm{PPh}_{3}\right)_{4}\right)$, and sodium carbonate were purchased from $\mathrm{Al}$ drich. All reagents purchased commercially were used without further purification, except for the toluene used as a solvent, which was distilled.

2.2. Measurements. Thermal gravimetric analysis (TGA) was performed under a nitrogen atmosphere at a heating rate of $10^{\circ} \mathrm{C} / \mathrm{min}$ using a Perkin Elmer TGA7 thermogravimetric analyzer. UV-Vis spectra were obtained using a Shimadzu $\mathrm{UV} /$ vis spectrometer. The polymer films used in the UV-Vis absorption measurements were prepared by spin coating of polymer solution in chlorobenzene. The optical energy band gaps $\left(E_{g}\right)$ were estimated from the absorption onset wavelengths $\left(E_{g}=1240 / \lambda_{\text {onset }}(\mathrm{eV})\right)$ of the polymer films. The electrochemical properties of the polymers were characterized by cyclic voltammetry $(\mathrm{CV})$. The films were prepared by dip coating the polymer solution onto Pt wire, and the measurements were calibrated using the ferrocene value of $-4.8 \mathrm{eV}$ as the standard [20]. Film thicknesses were measured using a TENCOR surface profiler.

2.3. Synthesis. The syntheses of the copolymers, poly $\left[\left(N-9^{\prime}-\right.\right.$

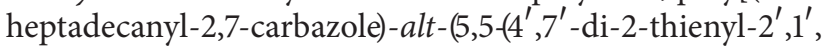
$3^{\prime}$-benzothiadiazole $\left.\left.)\right)\right]$ (PCz3TB), and three poly[(N-9'-heptadecanyl-2,7-carbazole)-co-(5,5-(4, $7^{\prime}$-di-2-thienyl-2', $1^{\prime}, 3^{\prime}$-benzothiadiazole)) -co- (3, 5-bis-(4-4-phenyl-[1, 2, 4]triazole))] (PCz3TBTz) were carried out using the Suzuki coupling reaction between the diborolanylaryl compound, 2,7-bis $\left(4^{\prime}\right.$, $4^{\prime}, 5^{\prime}, 5^{\prime}$-tetramethyl-1', $3^{\prime}, 2^{\prime}$-dioxaborolan-2' -yl)-N-9"'-heptadecanyl-carbazole $(\mathbf{C z})$, and the dibromoaryl compounds, 4,7-bis(5-bromothiophen-2-yl) benzo [c] $[1,2,5]$ thiadiazole (3TB) and 3,5-bis-(4-bromophenyl)-4-(4-butylphenyl)-4H$[1,2,4]$ triazole $(\mathbf{T z})$.

2.3.1. Synthesis of PCz3TB. Two comonomers, $\mathbf{C z}(0.25 \mathrm{~g}$, $0.38 \mathrm{mmol})$ and 3 TB $(0.12 \mathrm{~g}, 0.38 \mathrm{mmol})$, were dissolved in distilled toluene $(4.5 \mathrm{~mL})$ with the air-sensitive $\operatorname{Pd}(0)$ complex, $\mathrm{Pd}\left(\mathrm{PPh}_{3}\right)_{4}(0.004 \mathrm{~g}, 0.004 \mathrm{mmol})$. Aliquat336 (0.015 $\mathrm{g}, 0.037 \mathrm{mmol})$ and $2 \mathrm{M}$ aq. sodium carbonate $(0.18 \mathrm{~g}, 1.74$ $\mathrm{mmol})$ were added to the mixture. After being refluxed for $48 \mathrm{~h}$, the reaction mixture was cooled to about $50^{\circ} \mathrm{C}$ and added slowly to a vigorously stirred mixture consisting of 230 $\mathrm{mL}$ of methanol and $15 \mathrm{~mL}$ of $1 \mathrm{M}$ aq. $\mathrm{HCl}$. The polymer fibers were collected by filtration and reprecipitation from methanol. The polymer was purified by a Soxhlet extraction in acetone for 2 days to remove oligomers and catalyst residues. The reprecipitation procedure in dichloromethane/methanol was then repeated several times. The final product, a yellow polymer, was obtained after drying in vacuum at $60^{\circ} \mathrm{C}$, with a yield of $0.42 \mathrm{~g}(64.4 \%)$. Anal. Calcd. for $\left(\mathrm{C}_{43} \mathrm{H}_{47} \mathrm{~N}_{3} \mathrm{~S}_{3}\right)_{n}$ : C: $73.56, \mathrm{H}: 6.75, \mathrm{~N}: 5.99$, S: 13.70. Found: C: $65.48, \mathrm{H}: 5.97, \mathrm{~N}: 5.34, \mathrm{~S}: 11.01$.

2.3.2. Synthesis of PCz3TBTz-1. PCz3TBTz-1 was prepared as for PCz3TB, using three comonomers, $\mathbf{C z}(0.55 \mathrm{~g}, 0.84$ $\mathrm{mmol}), 3 \mathrm{~TB}(0.30 \mathrm{~g}, 0.65 \mathrm{mmol})$, and Tz $(0.08 \mathrm{~g}, 0.16 \mathrm{mmol})$, resulting in purple solid with a yield of $0.20 \mathrm{~g}(34.0 \%)$. Anal. Calcd. for $\left(\mathrm{C}_{225} \mathrm{H}_{250} \mathrm{~N}_{16} \mathrm{~S}_{12}\right)_{n}$ : C: 75.71, H: 7.06, N: 6.28, S: 10.96. Found: C: 74.23, H: 7.41, N: 5.69, S: 10.94 .

2.3.3. Synthesis of PCz3TBTz-2. PCz3TBTz-2 was prepared as for PCz3TBTz-1, using Cz (0.26 g, $0.39 \mathrm{mmol})$, 3TB (0.085 $\mathrm{g}, 0.19 \mathrm{mmol})$, and $\mathrm{Tz}(0.095 \mathrm{~g}, 0.19 \mathrm{mmol})$, resulting in purple solid with a yeld of $0.14 \mathrm{~g}$ (51.1\%). Anal. Calcd. for $\left(\mathrm{C}_{96} \mathrm{H}_{109} \mathrm{~N}_{7} \mathrm{~S}_{3}\right)_{n}$ : C: 78.93, H: 7.52, N: 6.71, S: 6.85. Found: C: 72.50, H: 6.81, N: 5.83, S: 6.99 .

2.3.4. Synthesis of PCz3TBTz-3. PCz3TBTz-3 was prepared as for PCz3TBTz-1 using Cz (0.26 g, $0.39 \mathrm{mmol})$, 3TB (0.034 $\mathrm{g}, 0.074 \mathrm{mmol})$, and $\mathrm{Tz}(0.15 \mathrm{~g}, 0.30 \mathrm{mmol})$, resulting in purple solid with a yield of $0.18 \mathrm{~g}(64.3 \%)$. Anal. Calcd. for $\left(\mathrm{C}_{255} \mathrm{H}_{295} \mathrm{~N}_{19} \mathrm{~S}_{3}\right)_{n}$ : C: 82.15, H: 7.97, N: 7.13, S: 2.74. Found: C: 79.19, H: 7.86, N: 6.85, S: 3.03 .

2.4. Fabrication of $O P V$ Device. The organic photovoltaic devices were fabricated with the configuration ITO/PEDOT: PSS $(40 \mathrm{~nm}) /$ polymer:PC ${ }_{71} \mathrm{BM}(60 \mathrm{~nm}) / \mathrm{LiF}(1 \mathrm{~nm}) / \mathrm{Al}(100$ $\mathrm{nm})$. The ITO-coated glass substrates were cleaned by ultrasonic treatment in deionized water, acetone, isopropyl alcohol, and methanol. The poly(ethylene dioxythiophene):polystyrene sulfonic acid (PEDOT:PSS) layer was spin-coated on the substrate and annealed at $140^{\circ} \mathrm{C}$ for $10 \mathrm{~min}$. The active layer consisting of copolymers and $[6,6]-$ phenyl- $\mathrm{C}_{71^{-}}$butyric acid methyl ester $\left(\mathrm{PC}_{71} \mathrm{BM}\right)$ was spin-coated from a chlorobenzene solution. Prior to use, a chlorobenzene solution of polymer and $\mathrm{PC}_{71} \mathrm{BM}$ with the total concentration of $20 \mathrm{mg} / \mathrm{mL}$ was stirred at room temperature overnight to ensure complete dissolution. The polymer solutions were spin-coated onto the substrate after being filtered through a $0.45 \mu \mathrm{m}$ polytetrafluoroethylene (PTFE) membrane syringe. Next, the LiF and Al layers were deposited as the cathode electrode. The area of the device was $4 \mathrm{~mm}^{2}$. After annealed at $100^{\circ} \mathrm{C}$ for $10 \mathrm{~min}$, the current-voltage $(J-V)$ characteristics of the polymer:PCBM films were measured with a Keithley 2400 source-measure unit in air under white light illumination of $\operatorname{AM} 1.5\left(100 \mathrm{~mW} / \mathrm{cm}^{2}\right)$.

\section{Results and Discussion}

3.1. Synthesis and Thermal Property. The syntheses of the carbazole-benzothiadiazole-triazole-based copolymers (PCz3TBTz-1, PCz3TBTz-2, and PCz3TBTz-3) were carried out using Suzuki coupling reaction between the diborolanylaryl compound, 2,7-bis $\left(4^{\prime}, 4^{\prime}, 5^{\prime}, 5^{\prime}\right.$-tetramethyl-1', $3^{\prime}, 2^{\prime}$ dioxaborolan-2'-yl)-N-9" -heptadecanyl-carbazole and the dibromoaryl compounds, 4,7-bis(5-bromothiophen-2-yl) benzo[c] $[1,2,5]$ thiadiazole (3BT) and 3,5-bis-(4-bromophenyl)-4-(4-butylphenyl)-4H-[1,2,4]triazole (Tz). The feed 


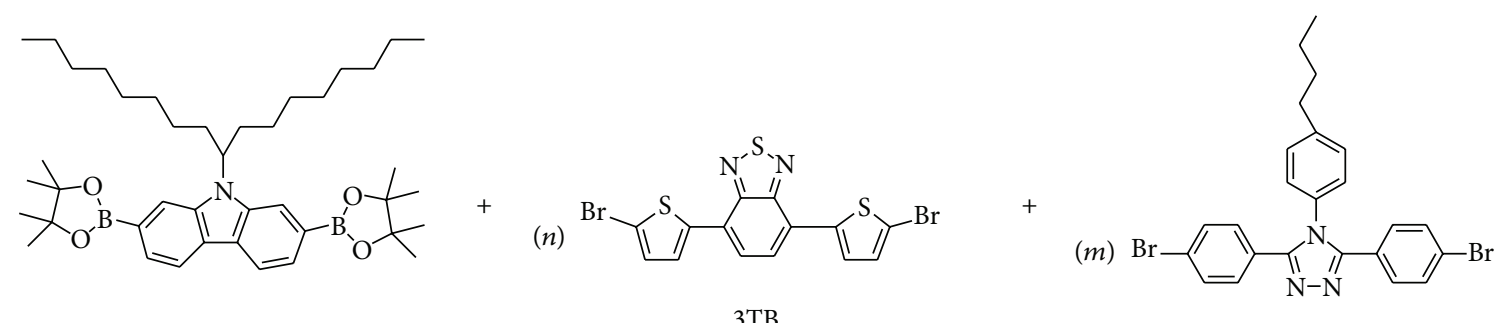

$\mathrm{Cz}$

$3 \mathrm{~TB}$

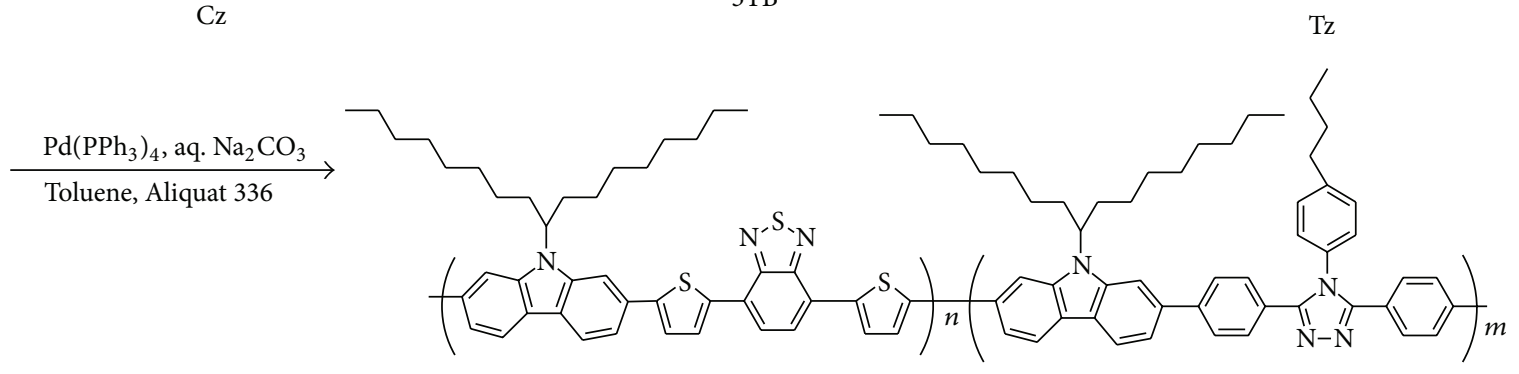

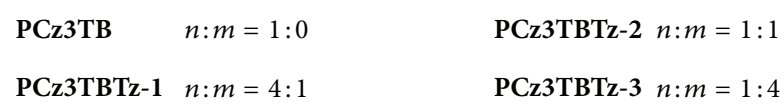

Scheme 1: Synthetic route to the PCz3TB and three PCz3TBTzs.

TABle 1: Physical properties of polymers.

\begin{tabular}{|c|c|c|c|c|}
\hline & PCz3TB & PCz3TBTz-1 & PCz3TBTz-2 & PCz3TBTz-3 \\
\hline \multicolumn{5}{|l|}{ Ratio $(\mathrm{Cz}: 3 \mathrm{~TB}: \mathrm{Tz})$} \\
\hline Feed ratio & $50: 50: 0$ & $50: 40: 10$ & $50: 25: 25$ & $50: 10: 40$ \\
\hline Actual ratio ${ }^{a}$ & $61: 39: 0$ & $62: 35: 3$ & $60: 24: 16$ & $56: 10: 34$ \\
\hline$M_{n}^{\mathrm{b}}$ & 94800 & 95300 & 77400 & 8300 \\
\hline$M_{w}{ }^{\mathrm{b}}$ & 121700 & 135100 & 110200 & 11700 \\
\hline $\operatorname{PDI}\left(M_{w} / M_{n}\right)$ & 1.28 & 1.42 & 1.42 & 1.41 \\
\hline$T_{5 \mathrm{~d}}\left({ }^{\circ} \mathrm{C}\right)$ & 361 & 359 & 354 & 369 \\
\hline Solution $\left(\lambda_{\max }, \mathrm{nm}\right)$ Abs. & 380,530 & 380,536 & 380,536 & 365,528 \\
\hline Film $\left(\lambda_{\max }, \mathrm{nm}\right)$ Abs. & 390,560 & 392,566 & 383,550 & 356,539 \\
\hline$E_{\text {onset }}(\mathrm{V} \text { versus } \mathrm{SCE})^{\mathrm{c}}$ & 0.98 & 0.96 & 0.99 & 0.92 \\
\hline $\operatorname{HOMO}(\mathrm{eV})^{\mathrm{d}}$ & -5.37 & -5.35 & -5.38 & -5.31 \\
\hline LUMO (eV) & -3.51 & -3.49 & -3.48 & -3.36 \\
\hline$E_{g}(\mathrm{eV})^{\mathrm{e}}$ & 1.86 & 1.86 & 1.90 & 1.95 \\
\hline
\end{tabular}

${ }^{a}$ Actual ratio in polymers determined by elemental analysis.

${ }^{\mathrm{b}} M_{n}$ and $M_{w}$ stand for the number-average and weight-average molecular weights, respectively, determined by GPC.

${ }^{\mathrm{c}} E_{\text {onset }}$ stands for onset potential of oxidation.

${ }^{\mathrm{d}}$ Calculated using the empirical equation: $I_{p}(\mathrm{HOMO})=-\left(E_{\text {onset }}+4.39\right)$.

${ }^{\mathrm{e}}$ Optical band gaps $\left(E_{g}\right)$ taken as the absorption onsets in the UV-vis spectra of the polymer films $\left(E_{g}=1240 / \lambda_{\text {onset }} \mathrm{eV}\right)$.

ratios of two dibromides (3BT and $\mathbf{T z}$ ) were varied from $4: 1,2: 2$, to $1: 4$ to assess the effect of triazole units on the OPV performance. For comparison, the well-known OPV donor polymer, PCz3TB, was also synthesized at the same time. Three PCz3TBTz copolymers have the same polymer backbone as PCz3TB. In the carbazole and 4,7-bis(5bromothiophen-2-yl)benzo[c] [1,2,5] thiadiazole (3BT) backbone, we incorporated an electron-transporting moiety, 4(4-butylphenyl)-4H-[1,2,4]triazole ( $\mathbf{T z}$ ), as the third comonomer. The synthetic routes toward copolymers are outlined in Scheme 1. Three PCz3TBTz copolymers were designed to have 10,25 , and $40 \%$ triazole unit content instead of $\mathbf{3}$ TB unit content; however, the actual ratios of the repeat units in the real copolymers could be different from the feed ratios due to the difference of reactivity between comonomers. An elemental analysis (EA) was used to calculate the actual ratio in the copolymers. PCz3TBTz-1, PCz3TBTz-2, and PCz3TBTz-3 contained 3, 16, and 34\% triazole unit content. The molecular weights, feed, and actual ratios of the repeat units in the copolymers are listed in Table 1 . The number-average $\left(M_{n}\right)$ and weight-average $\left(M_{w}\right)$ molecular weights of the synthesized polymers were determined with 


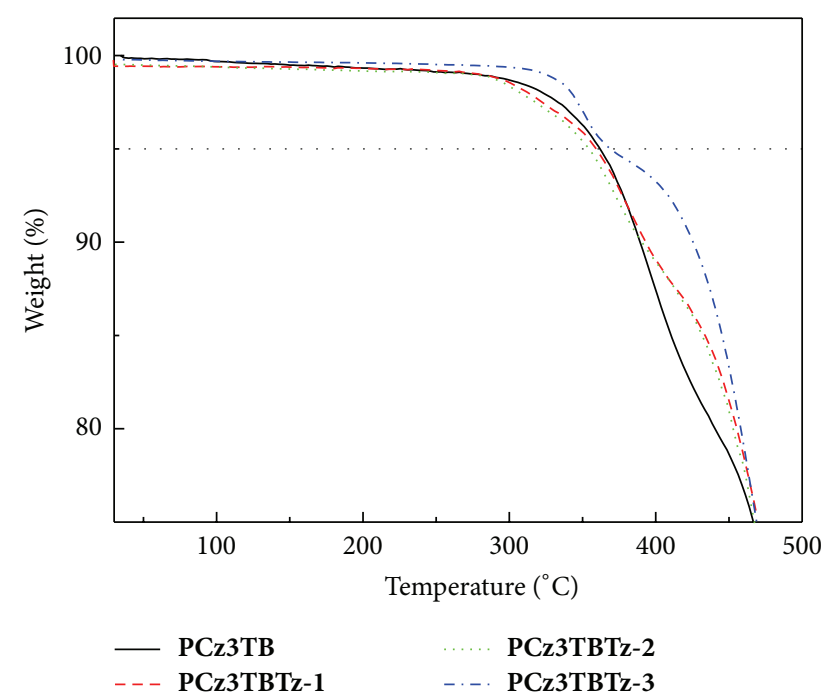

FIGURE 1: TGA thermograms of the copolymers.

gel permeation chromatography (GPC). The $M_{w}$ values of PCz3TB, PCz3TBTz-1, PCz3TBTz-2, and PCz3TBTz-3 were $121800,135100,110200$, and 11700, respectively, and their polydispersity indices (PDIs) ranged from 1.28 to 1.42 . The thermal stability of the copolymers was evaluated in a nitrogen atmosphere by TGA. As shown in Figure 1, the copolymers exhibited good thermal stability and the weight loss was less than $5 \%\left(T_{5 \mathrm{~d}}\right)$ upon heating to $350^{\circ} \mathrm{C}$.

3.2. Optical and Electrochemical Properties. The UV-Vis absorption spectra of four copolymers in chlorobenzene solutions with the dilute concentration are shown in Figure 2(a), and the main optical properties are listed in Table 1. All the UV-Vis absorption spectra have two absorption peaks, which could be assigned to the $\pi-\pi^{*}$ transition of the conjugated backbone and intramolecular charge transfer (ICT) interactions between the thiophene donor and the benzothiadiazole/triazole acceptor units [21]. The absorption spectra of the film state are red-shifted relative to those of the solution state (see Figure 2(b)), likely due to increased intermolecular interactions between neighboring molecules in the film state. By increasing the ratio of triazole in the copolymer from PCz3TB, PCz3TBTz-1, PCz3TBTz-2 to PCz3TBTz-3, the absorption intensity in the long wavelength region was gradually decreased. In other words, replacement of the benzothiadiazole moiety with the triazole moiety in the main chain exceeding $10 \%$ appeared to decrease interand intramolecular interactions between donor and acceptor moieties. The optical band gaps, $E_{g}$, of the copolymers are estimated from the absorption onset wavelengths of the UVVis spectrum of the polymer film (Table 1). The UV absorption and optical band gap of PCz3TBTz-1 are similar to those of PCz3TB, and greater addition of the triazole unit into the main chain in PCz3TBTz-2 and PCz3TBTz-3 resulted in an increase of the band gap of copolymers as compared to that of PCz3TB. The electrochemical properties of the polymers were also measured to determine their highest

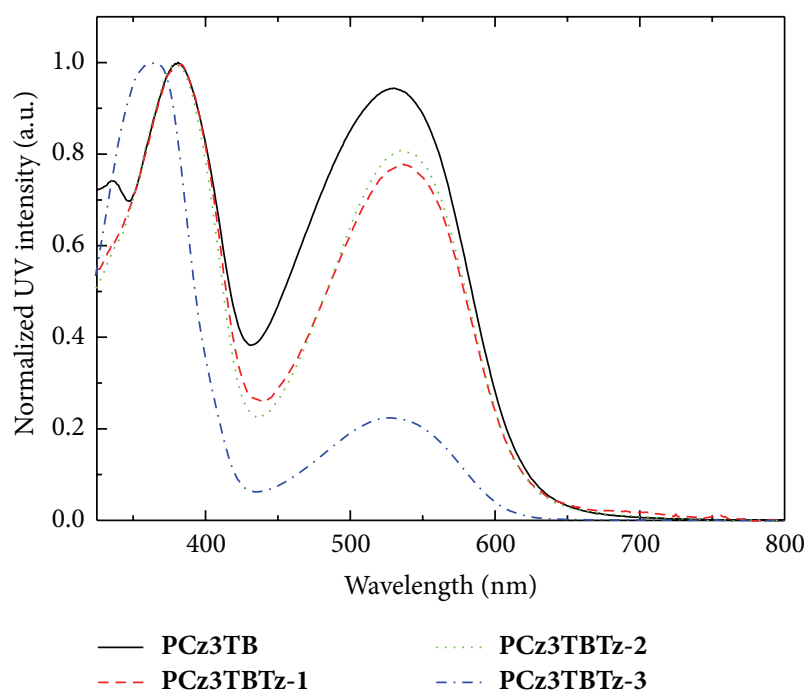

(a)

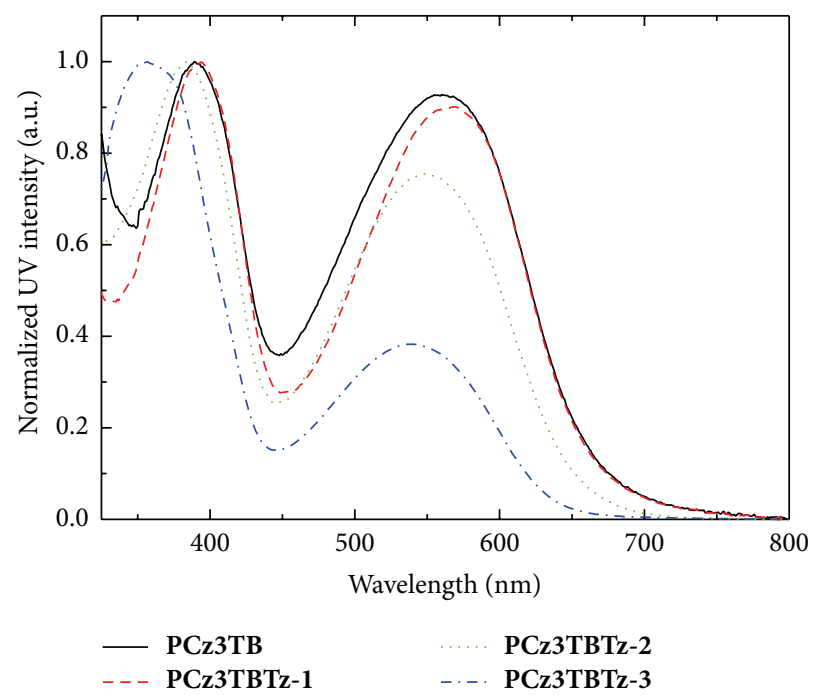

(b)

FIGURE 2: UV-Visible absorption spectra in (a) solution and (b) film.

occupied molecular orbital (HOMO) and the lowest unoccupied molecular orbital (LUMO) energy levels. Figure 3 shows the anodic scan of the CV of the copolymers. The onset of oxidation for copolymers occurred in a range of 0.92 to $0.98 \mathrm{~V}$ (vs SCE), which corresponds to their HOMO levels in a range of -5.31 to $-5.38 \mathrm{eV}$ (Table 1 ), according to the empirical relationship proposed by Leeuw et al. $I_{p}(\mathrm{HOMO})=-\left(E_{\text {onset }}+4.39\right)$, where $E_{\text {onset }}$ is the onset potential of oxidation [22]. The effects of the HOMO levels and band gaps on the photovoltaic properties are discussed below.

3.3. Organic Photovoltaic Properties. To investigate the current-voltage characteristics of the copolymers, devices with the configuration of ITO/PEDOT:PSS (40 nm)/polymer: $\mathrm{PC}_{71} \mathrm{BM}(60 \mathrm{~nm}) / \mathrm{LiF}(1 \mathrm{~nm}) / \mathrm{Al}(100 \mathrm{~nm})$ were fabricated. The blending ratio of polymer and PCBM was adjusted 


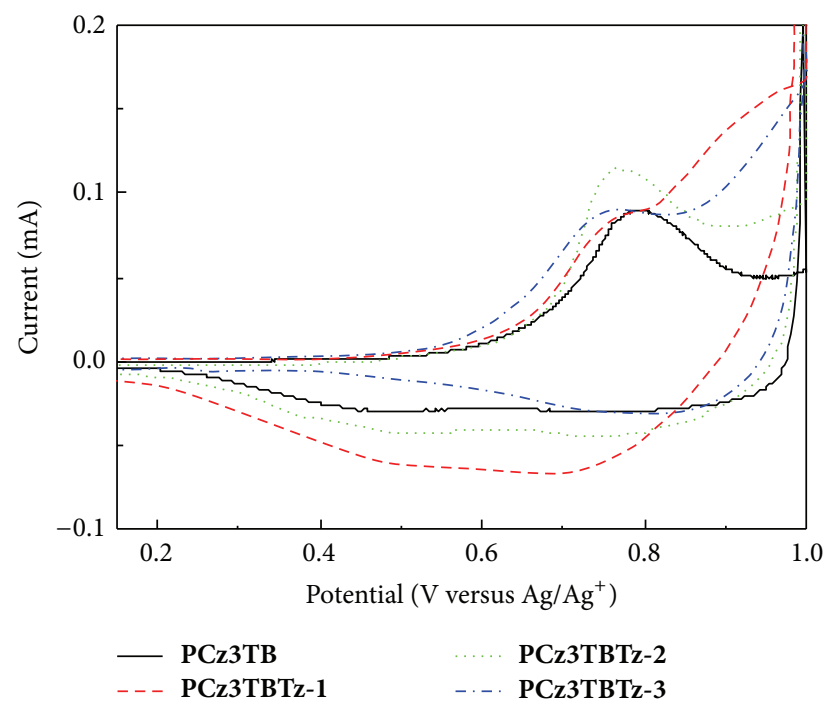

FIGURE 3: CV of the polymer films.

to be $1: 3$. Figure 4 shows the current density versus voltage $(J-V)$ curves for copolymer: PCBM devices and the photovoltaic properties of the blend films are summarized in Table 2. As shown in Figure 4, PCz3TBTz-1 showed the highest device performance, with a power conversion efficiency (PCE) of $1.74 \%$, compared to PCz3TB (1.55\%), PCz3TBTz-2 (0.98\%), and PCz3TBTz-3 (0.18\%). The device performances were attributed to increases of the short-circuit current $\left(J_{\mathrm{SC}}\right)$ and open-circuit voltage $\left(V_{\mathrm{OC}}\right)$ values. Despite a slight decrease of the $V_{\mathrm{OC}}$ value from $0.72 \mathrm{~V}$ (PCz3TB) to $0.66 \mathrm{~V}$ (PCz3TBTz-1), PCz3TBTz-1 showed a higher $J_{\mathrm{SC}}$ value of $6.36 \mathrm{~mA} / \mathrm{cm}^{2}$ than PCz3TB $\left(5.56 \mathrm{~mA} / \mathrm{cm}^{2}\right)$, and the $J_{\mathrm{SC}}$ and $V_{\mathrm{OC}}$ values gradually decreased by increasing the feed ratios of the triazole unit in PCz3TBTz-2 $\left(4.29 \mathrm{~mA} / \mathrm{cm}^{2}\right.$, $0.65 \mathrm{~V})$ and PCz3TBTz-3 $\left(1.21 \mathrm{~mA} / \mathrm{cm}^{2}, 0.46 \mathrm{~V}\right)$. As described above, although the UV absorption and optical band gap of PCz3TBTz-1 are similar with those of PCz3TB, PCz3TBTz-2 and PCz3TBTz-3 with more triazole units in the main chain showed lower UV absorption intensity in the long wavelength region and an increased optical band gap, compared with PCz3TB and PCz3TBTz-1. Low-bandgap conjugated materials with appropriate energy levels are required for efficient charge transfer in OPVs [23]. The gradually decreased efficiencies of PCz3TBTz-2 and PCz3TBTz3 relative to $\mathbf{P C z} 3 \mathrm{~TB}$ can be explained by the gradually decreased UV absorption intensity in the long wavelength region and the gradually increased band gaps. In addition, the significantly low efficiency of PCz3TBTz-3 might stem from its low molecular weight compared to the other copolymers.

In other words, the feed ratio of comonomer units of 3TB and Tz was optimized and the highest PCE of $1.74 \%$ was achieved in PCz3TBTz-1. This increased performance of PCz3TBTz-1 can be explained by its improved solubility and surface morphology. Figure 5 compares the surface morphologies of the PCz3TBTz-1:PCBM blend film with PCz3TB:PCBM blend film, determined from AFM measurements. The root-mean-square (RMS) roughness of the

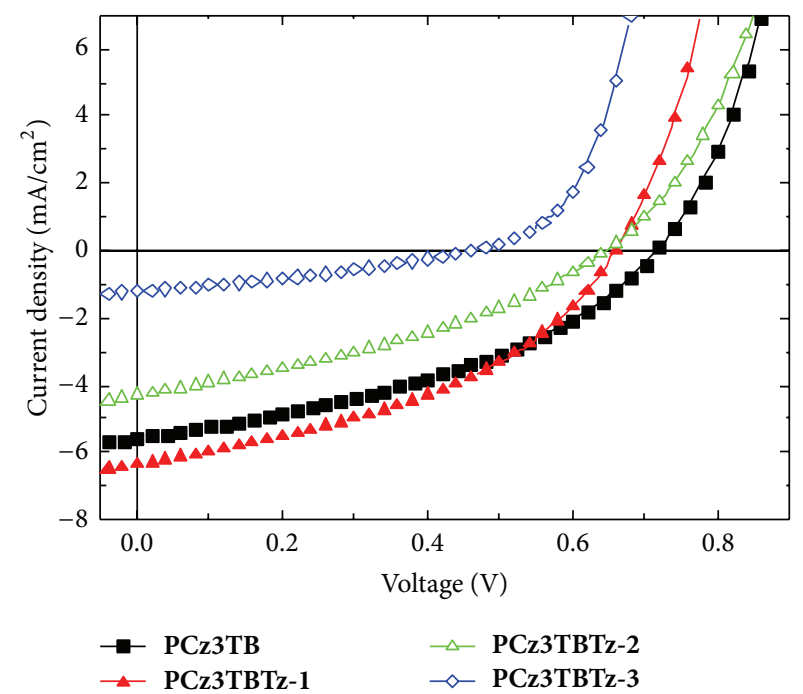

Figure 4: $J$ - $V$ curves of photovoltaic cells of copolymers.

TABLE 2: OPV performances of the polymer: $\mathrm{PC}_{71} \mathrm{BM}$ OPV cells ${ }^{\mathrm{a}, \mathrm{b}}$.

\begin{tabular}{lcccc}
\hline Active layer & $\begin{array}{c}J_{\mathrm{SC}} \\
\left(\mathrm{mA} / \mathrm{cm}^{2}\right)\end{array}$ & $\begin{array}{c}V_{\mathrm{OC}} \\
(\mathrm{V})\end{array}$ & $\begin{array}{c}\mathrm{FF} \\
(\%)\end{array}$ & $\begin{array}{c}\text { PCE } \\
(\%)\end{array}$ \\
\hline PCz3TB & 5.56 & 0.72 & 0.39 & $1.55(1.54)$ \\
PCz3TBTz-1 & 6.36 & 0.66 & 0.41 & $1.74(1.69)$ \\
PCz3TBTz-2 & 4.29 & 0.65 & 0.35 & $0.98(0.94)$ \\
PCz3TBTz-3 & 1.21 & 0.46 & 0.32 & $0.18(0.17)$ \\
\hline
\end{tabular}

${ }^{\mathrm{a}}$ Thickness of the active layer was adjusted to $60 \mathrm{~nm}$ (blend ratio: polymer: PCBM $=1: 3$ ).

${ }^{b}$ The values shown here are for the best device, and the average performances among three samples are also shown in parenthesis.

PCz3TBTz-1:PCBM film was $1.78 \mathrm{~nm}$, which was nearly ten times that of the PCz3TB:PCBM film. Similar phenomenon was observed in our previous work with PF3TB and PF3TBTz [18]. The larger RMS value of PCz3TBTz-1 suggests that it has rougher surface morphology, indicative of increased polymer aggregation [24]. The suitable phase separation by polymer aggregation facilitated improved charge transport and carrier collection efficiency, resulting in reduced charge recombination and an increased $J_{\mathrm{SC}}$ value in the device [15]. The better morphology of PCz3TBTz$\mathbf{1}$ is ascribed to improved solubility by introduction of the alkyl-substituted triazole unit into the main chain. Further research on modification of the polymer structure is currently underway.

\section{Conclusions}

We synthesized three carbazole-benzothiadiazole-based copolymers containing different amounts of triazole into the main chains through palladium-catalyzed Suzuki polymerization. The absorption intensity of the copolymers varied according to the amount of triazole. The feed ratio of comonomer units was optimized and the highest PCE of $1.74 \%$ 

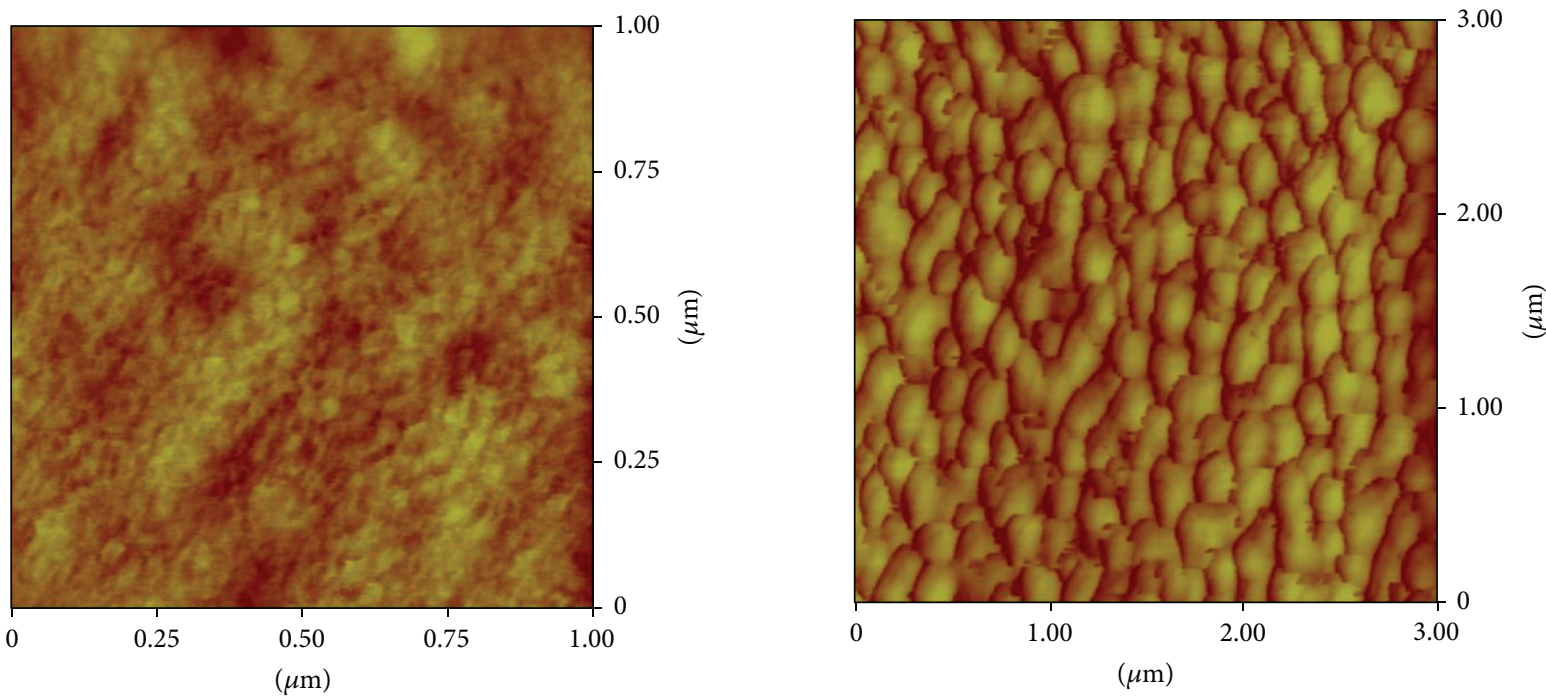

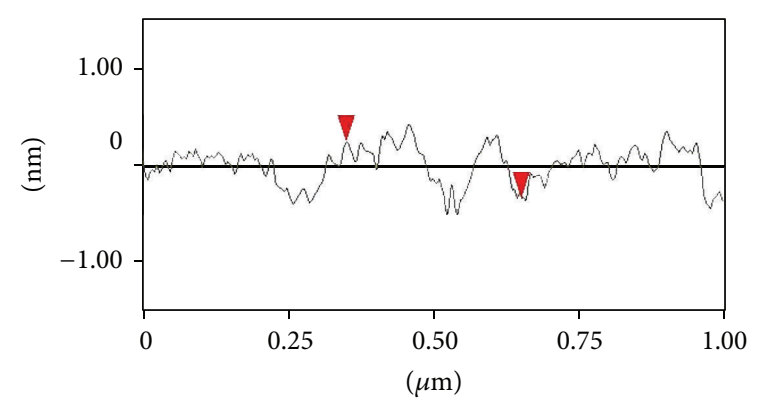

(a)

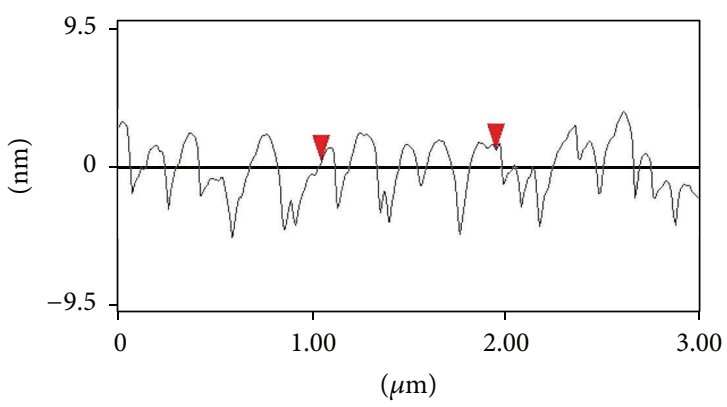

(b)

Figure 5: Topographic AFM images of (a) PCz3TB:PCBM and (b) PCz3TBTz-1:PCBM films.

was achieved in PCz3TBTz-1. This is attributed to its better morphology and solubility.

\section{Acknowledgment}

This research was supported by Basic Science Research Program through the National Research Foundation of Korea (NRF) funded by the Ministry of Education, Science and Technology (2012R1A1A3005083).

\section{References}

[1] R. L. Uy, S. C. Price, and W. You, "Structure-property optimizations in donor polymers via electronics, substituents, and side chains toward high efficiency solar cells," Macromolecular Rapid Communications, vol. 33, no. 14, pp. 1162-1177, 2012.

[2] G. Dennler, M. C. Scharber, and C. J. Brabec, "Polymer-fullerene bulk-heterojunction solar cells," Advanced Materials, vol. 21, no. 13, pp. 1323-1338, 2009.

[3] P.-L. T. Boudreault, A. Najari, and M. Leclerc, "Processable lowbandgap polymers for photovoltaic applications," Chemistry of Materials, vol. 23, no. 3, pp. 456-469, 2011.

[4] J. A. Kong, E. Lim, K. K. Lee, S. Lee, and S. H. Kim, "A benzothiadiazole-based oligothiophene for vacuum-deposited organic photovoltaic cells," Solar Energy Materials and Solar Cells, vol. 94, no. 12, pp. 2057-2063, 2010.
[5] C. L. Chochos and S. A. Choulis, "How the structural deviations on the backbone of conjugated polymers influence their optoelectronic properties and photovoltaic performance," Progress in Polymer Science, vol. 36, no. 10, pp. 1326-1414, 2011.

[6] J. Y. Lee, S. M. Lee, K. W. Song, and D. K. Moon, "Synthesis and photovoltaic property of polymer semiconductor with phthalimide derivative as a promising electron withdrawing material," European Polymer Journal, vol. 48, no. 3, pp. 532-540, 2012.

[7] R. C. Coffin, J. Peet, J. Rogers, and G. C. Bazan, "Streamlined microwave-assisted preparation of narrow-bandgap conjugated polymers for high-performance bulk heterojunction solar cells," Nature Chemistry, vol. 1, no. 8, pp. 657-661, 2009.

[8] K. H. Hendriks, W. Li, M. M. Wienk, and R. A. J. Janssen, "Band gap control in diketopyrrolopyrrole-based polymer solar cells using electron donating side chains," Advanced Energy Materials, vol. 3, no. 5, pp. 674-679, 2013.

[9] S. W. Kim, S. C. Shim, B.-J. Jung, and H.-K. Shim, "Synthesis and properties of new electroluminescent polymers possessing both hole and electron-transporting units in the main chain," Polymer, vol. 43, no. 15, pp. 4297-4305, 2002.

[10] E. Lim, B.-J. Jung, and H.-K. Shim, "Improved EL efficiency of fluorene-thieno[3,2-b] thiophene-based conjugated copolymers with hole-transporting or electron-transporting units in the main chain," Journal of Polymer Science A, vol. 44, no. 1, pp. 243-253, 2006.

[11] H. L. Zhong, S. W. Man, H. Fukutani, and Y. Tao, "Synthesis and light-emitting properties of bipolar oligofluorenes containing 
triarylamine and 1,2,4-triazole moieties," Organic Letters, vol. 8, no. 19, pp. 4271-4274, 2006.

[12] Y.-T. Chang, S.-L. Hsu, G.-Y. Chen et al., "Intramolecular donor-acceptor regioregular poly(3-hexylthiophene)s presenting octylphenanthrenyl-imidazole moieties exhibit enhanced charge transfer for heterojunction solar cell applications," Advanced Functional Materials, vol. 18, no. 16, pp. 2356-2365, 2008.

[13] S. Wen, J. Pei, Y. Zhou et al., "Synthesis and photovoltaic properties of poly(p-phenylenevinylene) derivatives containing oxadiazole," Journal of Polymer Science A, vol. 47, no. 4, pp. 10031012, 2009.

[14] B. Zhao, D. Liu, L. Peng et al., "Effect of oxadiazole side chains based on alternating fluorene-thiophene copolymers for photovoltaic cells," European Polymer Journal, vol. 45, no. 7, pp. 2079-2086, 2009.

[15] H.-S. Wang, M.-S. Su, and K.-H. Wei, "Synthesis and characterization of donor-acceptor poly(3-hexylthiophene) copolymers presenting 1,3,4-oxadiazole units and their application to photovoltaic cells," Journal of Polymer Science A, vol. 48, no. 15, pp. 3331-3339, 2010.

[16] T. Higashihara, H.-C. Wu, T. Mizobe, C. Lu, M. Ueda, and W.C. Chen, "Synthesis of thiophene-based $\pi$-conjugated polymers containing oxadiazole or thiadiazole moieties and their application to organic photovoltaics," Macromolecules, vol. 45, no. 22, pp. 9046-9055, 2012.

[17] E. Lim, S. Lee, and K. K. Lee, "Improved OPV efficiency of fluorene-thiophene-based copolymers with hole- and electrontransporting units in the main chain," Molecular Crystals and Liquid Crystals, vol. 538, pp. 157-163, 2011.

[18] E. Lim, K. K. Lee, and S. Lee, "Improved photovoltaic properties of fluorene-thiophene-based copolymers by an electrontransporting triazole unit in the main chain," Journal of Nanoscience and Nanotechnology, vol. 12, no. 4, pp. 3483-3487, 2012.

[19] J.-Y. Choi, D.-H. Kim, B. Lee, and J.-H. Kim, "Synthesis and electro-optical properties of $\pi$-conjugated polymer based on 10 hexylphenothiazine and aromatic 1,2,4-triazole," Bulletin of the Korean Chemical Society, vol. 30, no. 9, pp. 1933-1938, 2009.

[20] J. Pommerehne, H. Vestweber, W. Guss et al., "Efficient two layer LEDs on a polymer blend basis," Advanced Materials, vol. 7, no. 6, pp. 551-554, 1995.

[21] Y. Li, L. Xue, H. Li et al., "Energy level and molecular structure engineering of conjugated donor-acceptor copolymers for photovoltaic applications," Macromolecules, vol. 42, no. 13, pp. 4491-4499, 2009.

[22] D. M. de Leeuw, M. M. J. Simenon, A. R. Brown, and R. E. F. Einerhand, "Stability of n-type doped conducting polymers and consequences for polymeric microelectronic devices," Synthetic Metals, vol. 87, no. 1, pp. 53-59, 1997.

[23] B. C. Thompson and J. M. J. Fréchet, "Polymer-fullerene composite solar cells," Angewandte Chemie International Edition, vol. 47, no. 1, pp. 58-77, 2007.

[24] G. Li, V. Shrotriya, J. Huang et al., "High-efficiency solution processable polymer photovoltaic cells by self-organization of polymer blends," Nature Materials, vol. 4, no. 11, pp. 864-868, 2005. 

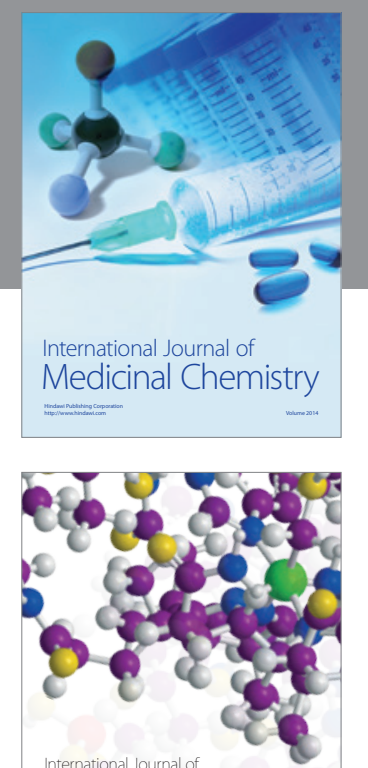

\section{Carbohydrate} Chemistry

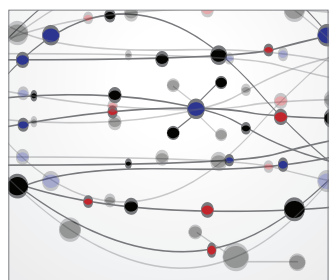

The Scientific World Journal
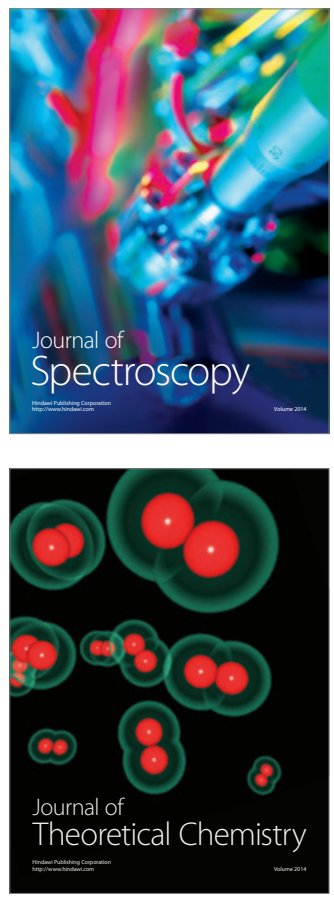
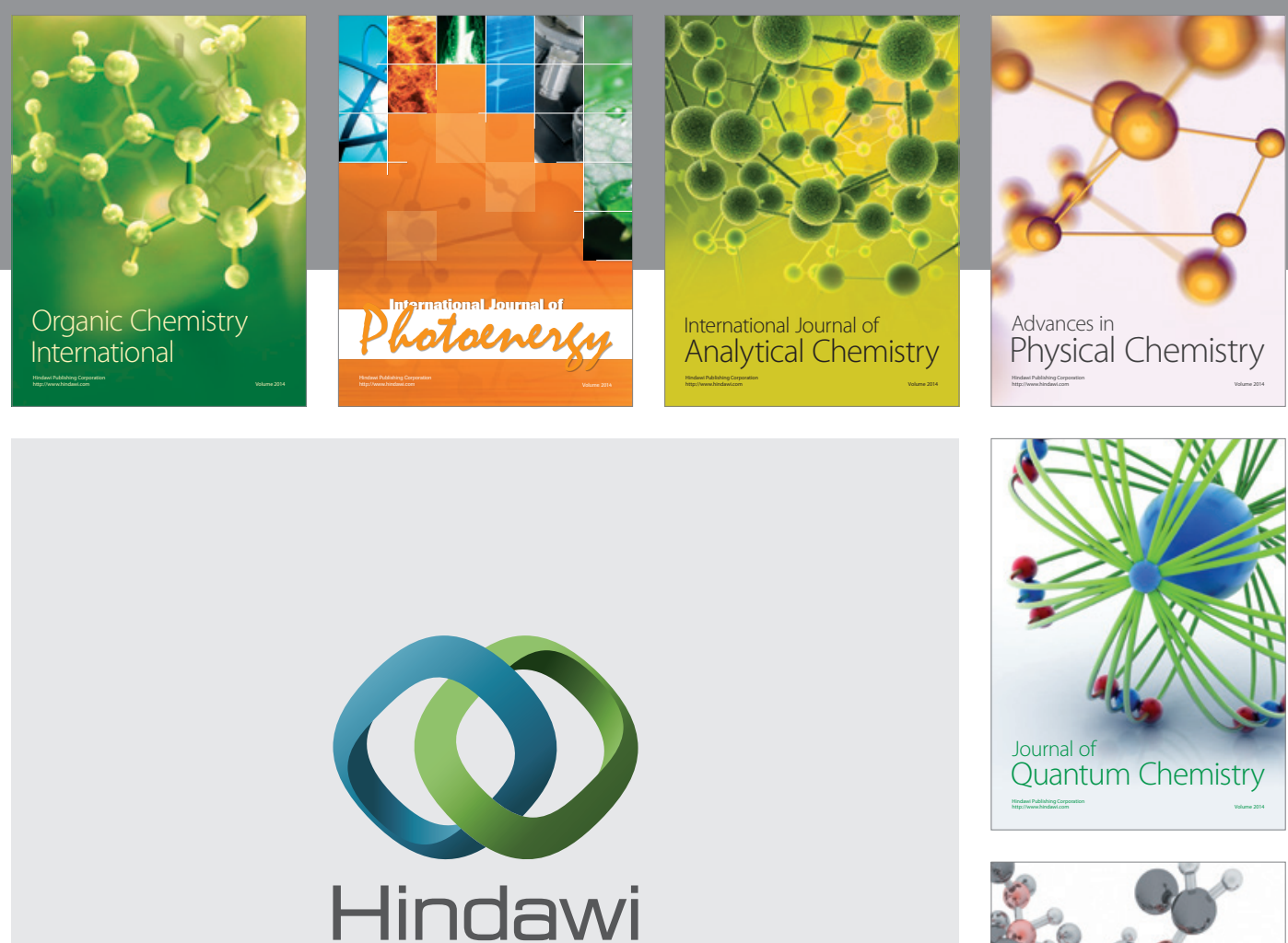

Submit your manuscripts at

http://www.hindawi.com

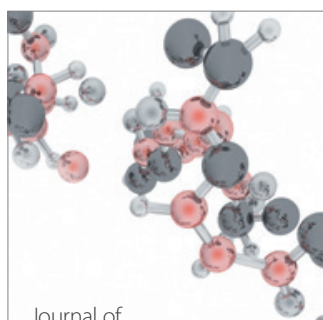

Analytical Methods

in Chemistry

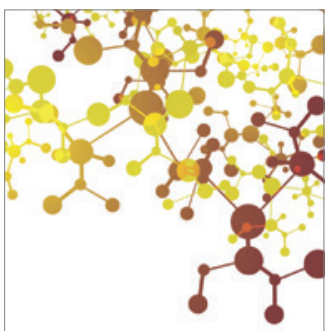

Journal of

Applied Chemistry

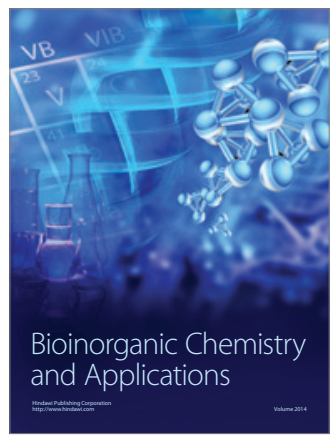

Inorganic Chemistry
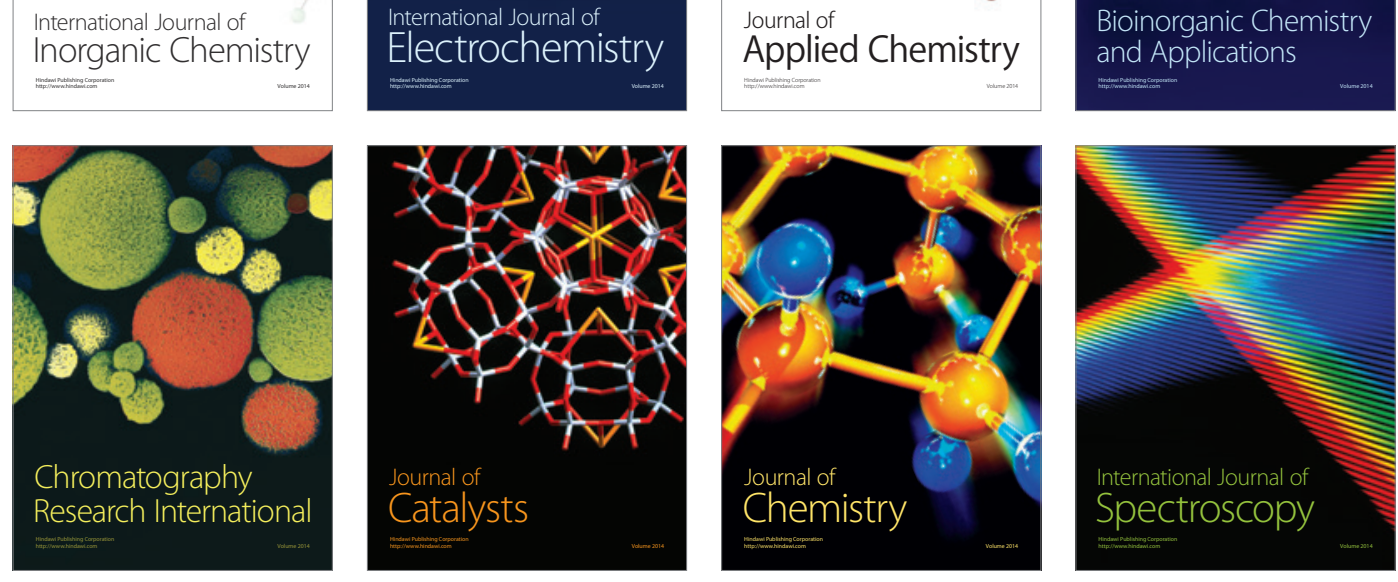